\title{
Correction to: The trade of glass beads in early medieval Illyricum: towards an Islamic monopoly
}

\author{
Elisabetta Neri ${ }^{1} \cdot$ Bernard Gratuze $^{1} \cdot$ Nadine Schibille $^{1}$
}

Published online: 14 April 2018

(C) Springer-Verlag GmbH Germany, part of Springer Nature 2018

Correction to: Archaeological and Anthropological Sciences https://doi.org/10.1007/s12520-017-0583-5

The original online version of the above article contained minor errors in Table 2 (samples K_013, K_018, K_019 and Lz_012). The corrected table is given below.

The online version of the original article can be found at https://doi.org/ $10.1007 / \mathrm{s} 12520-017-0583-5$

Elisabetta Neri

eneri@cnrs-orleans.fr

$\triangle$ Nadine Schibille

nadine.schibille@cnrs-orleans.fr

1 IRAMAT-CEB, UMR5060, CNRS/Université d'Orléans, 3D, rue de la Férollerie, 45071 Orléans cedex 2, France 


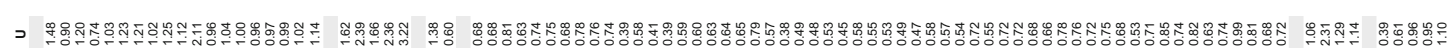

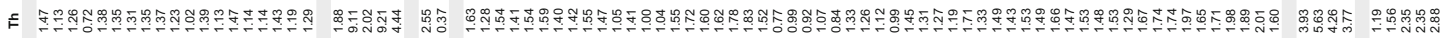

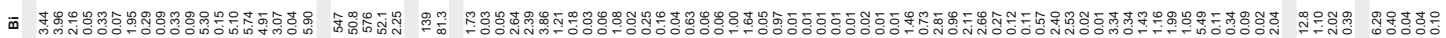

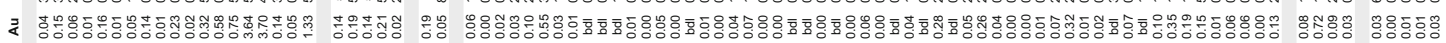

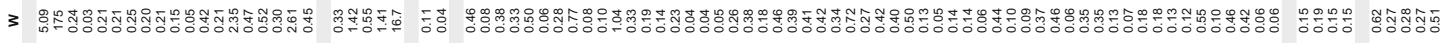

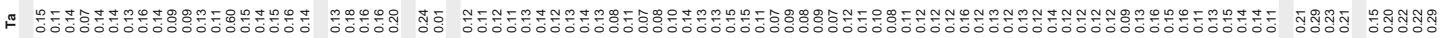

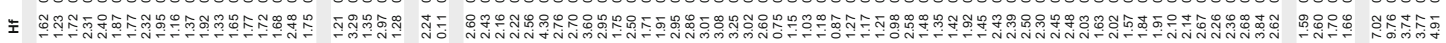

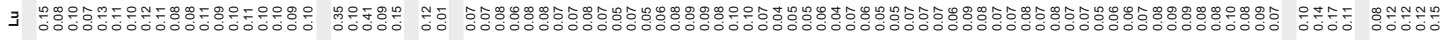

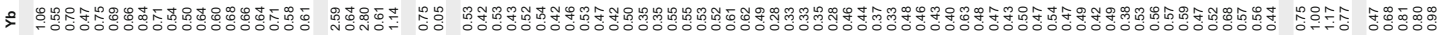

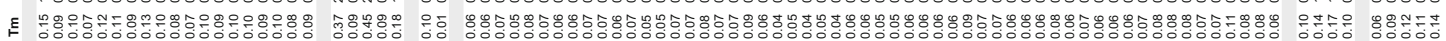

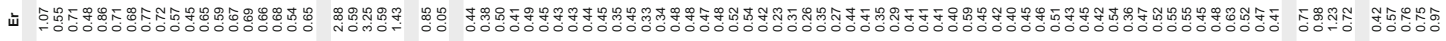

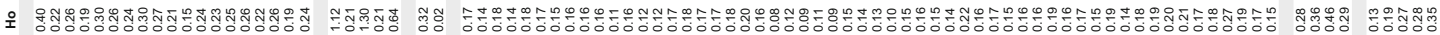

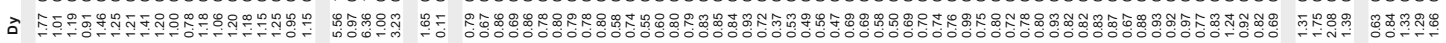

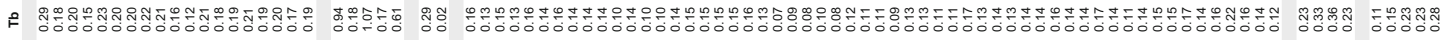

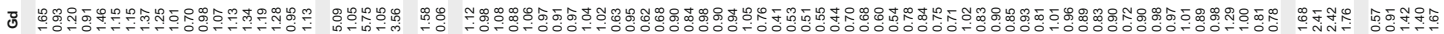

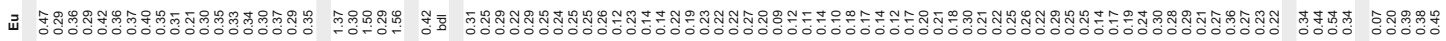

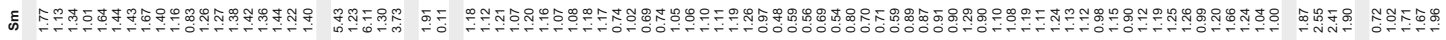

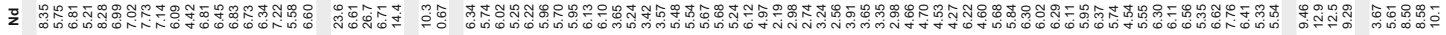

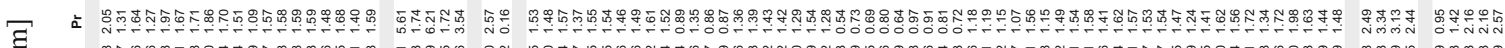

运 \&

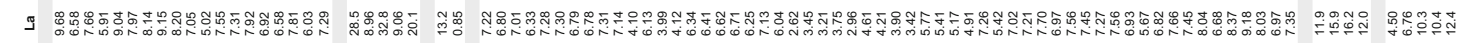

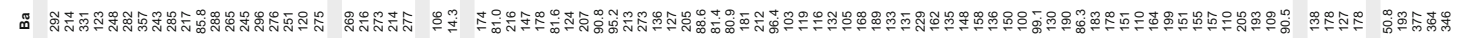

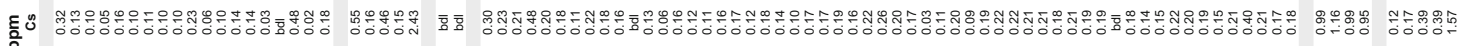

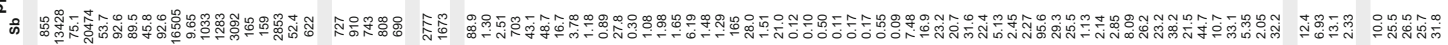

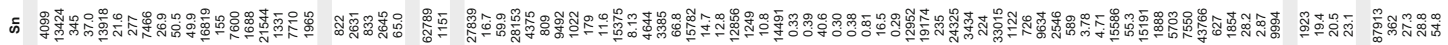

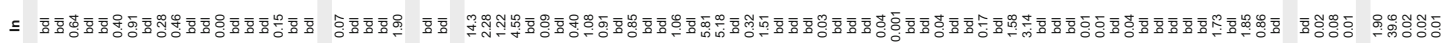

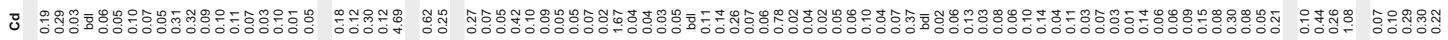

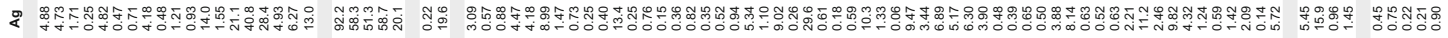

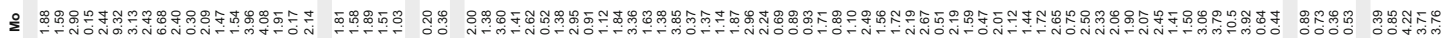

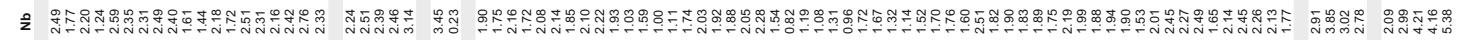

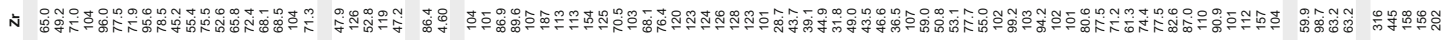

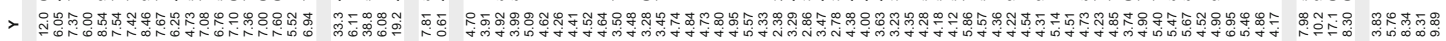

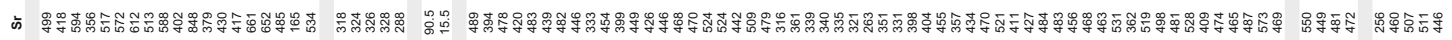

赵

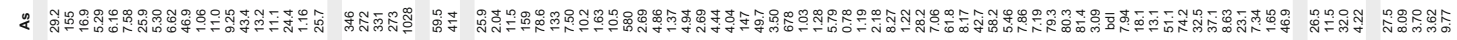

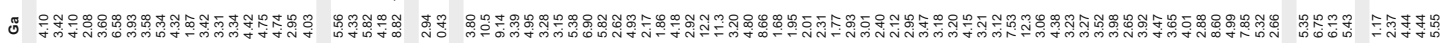

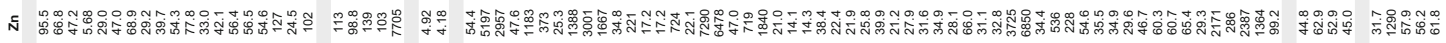

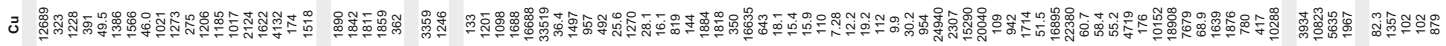

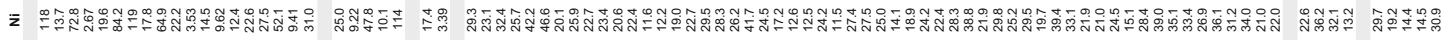

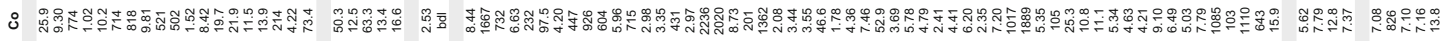

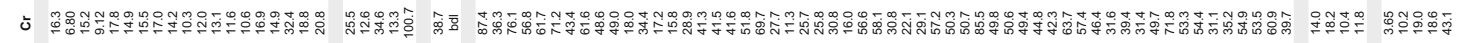

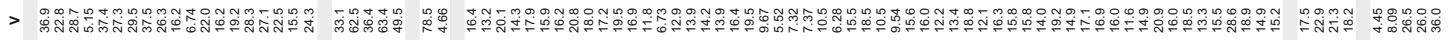

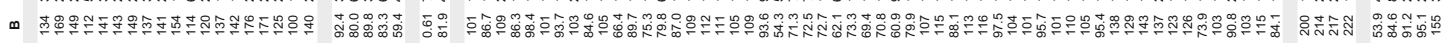

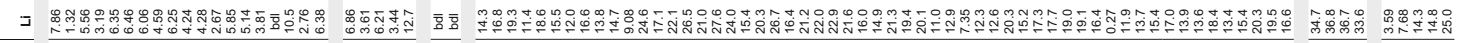

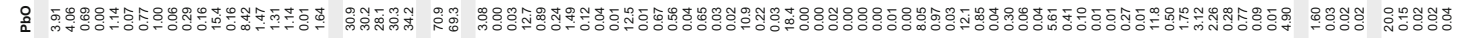

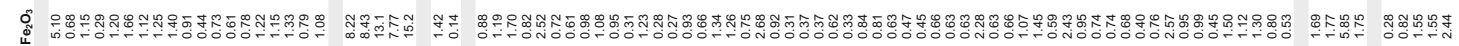

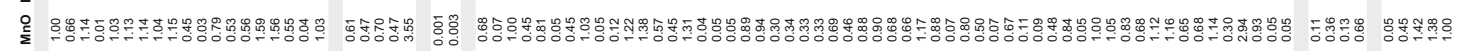

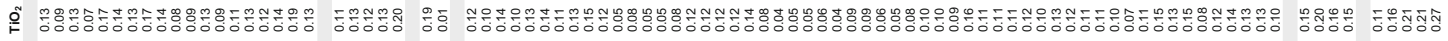

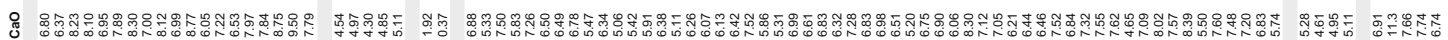

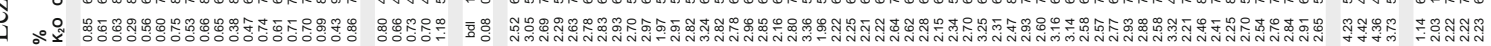

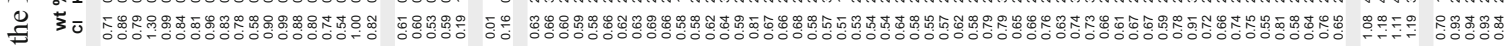

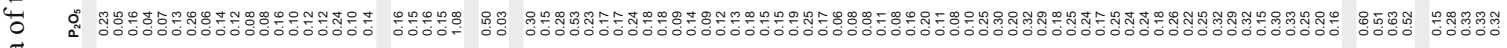

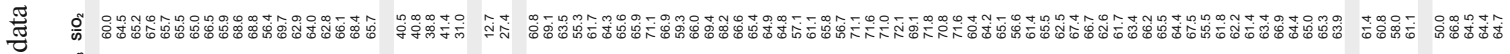

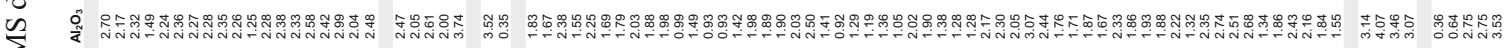

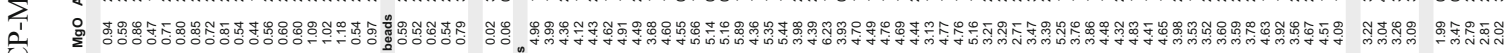

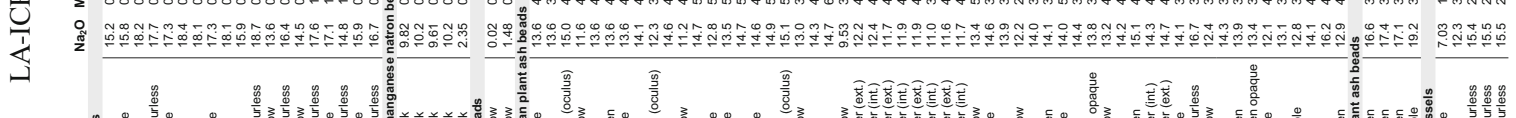

气 f

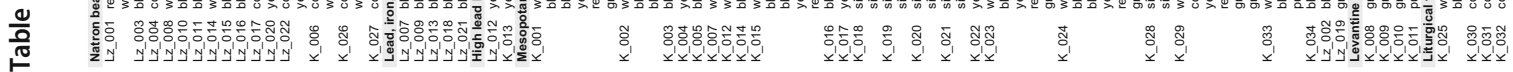

